\section{Diagnosis of Sarcoidosis by Labial Gland Biopsy}

\section{G. R. V. HUGHES， N. J. GROSS}

British Medical fournal, 1972, 3, 215

Pathological changes in the minor salivary glands of the lip reflect those of the major salivary glands (Waterhouse and Doniach, 1966). Labial gland biopsy, a simple and relatively safe procedure requiring only a small incision inside the lip, has proved a useful aid to the diagnosis of Sjögren's syndrome (Chisholm and Mason, 1968; Whaley et al., 1968). In this report lip biopsy was used to obtain histological confirmation of the diagnosis of sarcoidosis.

\section{Case report}

A 50-year-old man presented with a two-month history of arthritis affecting both knees and ankles associated with a low-grade fever On examination he was found to have synovitis of the knees and ankles, erythema over both medial malleoli, and bilateral en-

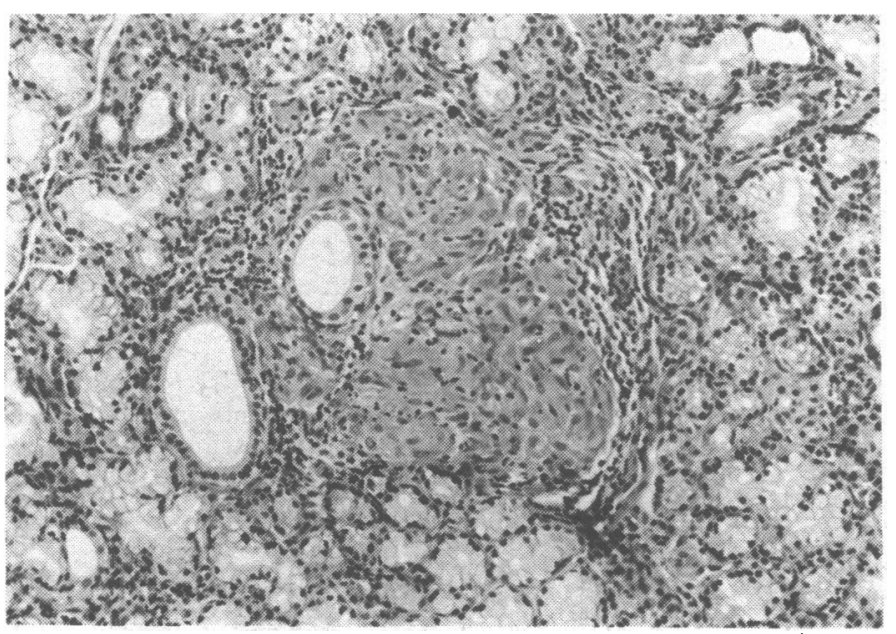

Labial salivary gland showing non-caseating granuloma. ( $x$ 143.)

Department of Medicine, Royal Postgraduate Medical School, London $\mathbf{W . 1 2}$

G. R. V. HUGHES, M.B., M.R.C.P., Senior Registrar and Clinical Tutor

N. in Medicine address: Department of Medicine, University of Chicago, 950 East 59th Street, Chicago, Illinois) largement of the parotid glands. The liver and spleen were not palpable. He was found to have a persistent fever $101^{\circ} \mathrm{F}\left(38.3^{\circ}\right.$ C). Chest $x$-ray examination showed bilateral hilar adenopathy. The tuberculin skin test was negative at 1 in 100 .

A clinical diagnosis of sarcoidosis was made, and because of the severity of the symptoms early histological confirmation was sought. In view of the parotid gland enlargement and the possibility that histological diagnosis might be made from salivary tissue a labial biopsy was performed. This showed involvement of the lip gland with multiple non-caseating granulomata (see Fig.) Similar findings were subsequently obtained from the liver biopsy. Four weeks later the Kveim reaction was strongly positive. The patient was treated with phenylbutazone and subsequently with corticosteroids with benefit.

A second patient with histologically-proved sarcolidosis and a similar clinical picture but without parotid gland enlargement had histologically normal labial gland.

\section{Comment}

The labial salivary glands can often be felt as pin-head sized lumps inside the lower lip. Under local anaesthesia a small incision is made and the gland removed. One silk suture can be removed in four or five days.

Chisholm and Mason (1968) showed the technique to be of value in the diagnosis and assessment of Sjögren's syndrome, where the lymphoid infiltration and secondary glandular changes are seen in the minor as well as the major salivary glands. The procedure appears to be safe from the complication of salivary fistula formation.

The salivary glands are involved in some $3-10 \%$ of patients with sarcoidosis (James, 1959; Crick et al., 1961). Sarcoid tubercles have also been found in the lacharymal glands in two cases of sarcoidosis with keratoconjunctivitis sicca (Crick et al., 1961). It may be that labial gland biopsy will provide histological confirmation only in cases of sarcoidosis where the major salivary glands are clinically involved. However, in view of its safety compared with liver biopsy, an assessment of the value of this technique in the diagnosis of sarcoidosis is now in progress.

We would like to thank Professor E. Bywaters, Professor J. Scadding, and Dr. A. Breckenridge for their advice. The Kveim reaction test was kindly performed by Dr. Donald Mitchell.

\section{References}

Chisholm, D. M., and Mason, D. K. (1968). fournal of Clinical Pathology, 21, 656.

Crick, R., Hoyle, C., and Smellie, H. (1961). British fournal of Ophthalmology, 45, 461.

James, D. G. (1959). American fournal of Medicine, 26, 331.

Waterhouse, J. P., and Doniach, I. (1966). Fournal of Pathology and Bacteriology, 91, 53.

Whaley, K., Chisholm, D. M., Downie, W. W., Dick, W. C., and Williamson, J. (1968). Acta Rheumatica Scandinavica, 14, 298. 